\title{
Controller for a SPS machine: a proposal PI control
}

Nathyely Marisol León-Lugo ${ }^{1}$, Sergio Alberto Torres-Vázquez ${ }^{2}$

\author{
${ }^{1}$ Procesos Induatriales, ICA Instituto Politécnico Nacional, Av. Luís Enrique Erro, Edifício 2 PB. Unidad Profesional \\ Adolfo López Mateos, Zacatenco, Gustavo A. Madero, CP 07738, Cidade do México, Cidade do México, México. \\ e-mail: nleon@ipn.mx \\ ${ }^{2}$ Procesos Industriales, ICA Instituto Politécnico Nacional, Av. Luís Enrique Erro, Edifício 2 PB. Unidad Profesional \\ Adolfo López Mateos, Zacatenco, Gustavo A. Madero, CP 07738, Cidade do México, Cidade do México, México. \\ e-mail: lanix@gmail.com
}

\section{ABSTRACT}

Temperature control is the key to effective sintering process for metal, ceramic and polymer powders. The original control temperature provides an irregular control operation process which affects the material properties due to the spacer involved in it.

Furthermore, it is analyzed how the material responds to an electrical input determining a model system with the variables implicated during the process in order to propose an efficient controller. The electrical current passed through a graphite matrix, it contains a compressed powder, so Joule effect is used for resistive heating. This article investigates how temperature control may be improved by a PI feedback controller, it was applied and simulated to the process and control gains were calculated analytically. Finally, the implemented PI controller is compared with the original model to observe the system stability, so that the operational limits are not overtaken maintaining the temperature below the reference.

Keywords: Spark Plasma Sintering (SPS), PI control.

\section{INTRODUCTION}

When Georg S. Ohm (1787-1854) published Die galvanische Kette mathematisch bearbeitet in 1827, he described the theory and applications of electric current. For his achievements, the German scientists name has been forever attributed to electrical science terminology: Ohms Law (1) states the proportionality of current and voltage in a resistor and the SI unit of resistance is the Ohm.

The introduction should present the paper theme, justifying the aim based on literature. It should also present the paper objectives.

$$
V=I R
$$

Ohms work provides a direct correlation between the potential voltage drop, V, across a resistive (or Ohmic) material, R, and the electric current, I, flowing through the medium. Moreover, Ohms Law is a fundamental concept that helped establish the basis of modern electrical theory. James Joule (1818-1889) coupled Ohms Law with his own endeavors in relating heat to mechanical work. Joule worked with Lord Kelvin in developing the absolute temperature scale $(\mathrm{K})$ and was also acknowledged for his contributions that eventually led to the First Law of Thermodynamics. His experiments initiated the concept of the mechanical equivalence of heat, which relates the energy required to raise the temperature of water 1F. Accordingly, the SI unit of work was named the Joule (J).

However, Joule might be best remembered for his discovery of the relationship, appropriately named Joules Law, between current flow and heat dissipation in a resistive element (2). Specifically, Joule found that the rate of thermal energy generated, E, within a resistive material, is proportional to the square of the current, I, and directly proportional to the resistance, R.

$$
E=I^{2} R
$$

Together, Georg Ohms and James Joules accomplishments close the gap between electrical energy input (either as a voltage potential or an electric current) and thermal energy output. $\mathrm{A}_{\mathrm{S}}$ a result, resistive 
heating can provide both undesired and desired heat generation. Because of Joules Law, resistive heating occurs whenever an electric current passes through a resistive material. The design of electronic circuitry must account for this phenomena or the risk of overheating, even melting, the hardware becomes a reality. On the other hand, Joules law sets forth the notion that the amount of thermal energy generated can be controlled by the inherent resistance of the heating element as well as the applied electric current [1,2].

When an electric field is applied to a material, the motion of electric charges within the material generates current flow. However, all materials exhibit some resistance, R, to this charge motion. Resistance, then, depends on both the resistive nature of a given material, called electrical resistivity, and the geometry of the material [3].

$$
R=\rho \frac{l}{A}
$$

Equation 3 shows that the resistance of a heating element is proportional to its length, 1, and inversely proportional to its cross-sectional area, A. Further, the electrical resistivity, $\rho$, for a given material is a function of temperature. The electrical conductivity is a measure of the materials ability to allow electrical current to flow and is defined as the reciprocal of resistivity (4).

$$
\sigma_{e}=\frac{1}{\rho}
$$

The temperature of the material is directly proportional to the amount of heat generated within it. In addition, the heat generated within the material is proportional to the power supplied to the material. This relation, then, states that the temperature attained is also linearly proportional to the power supplied (5) [4].

$$
P=V I=I^{2} R=\frac{V}{R^{2}}
$$

\section{DEVELOPMENT OF THE SYSTEM}

For open-loop control to be effective, an accurate model of the controlled object must be known. In resistive heating, especially in Sintering Process, a material can be developed as a function of applied voltage such as graphite.

The resistive element of known dimensions (length $\mathrm{L}$ and cross-sectional area $\mathrm{A}_{\mathrm{S}}$ ) and material parameters (resistivity $\rho$ and specific heat $C_{p}$ ) is subjected to an applied voltage $V$ which results in a current I, flowing through the sample. This model accounts for the heat generated $\mathrm{q}_{\mathrm{g}}$ by Joule Effect heating and the heat given off due to free convection qc. Furthermore, it is assumed that heat conduction in the radial direction and thermal radiation from the sample are negligible [4,5].

The first law of thermodynamics (6), which demands conservation of energy, is then applied to the resistive element [6].

$$
\Delta \dot{E}=\dot{E}_{\text {out }}-\dot{E}_{\text {in }}
$$

For this process, the heat generated, $\mathrm{q}_{\mathrm{g}}$, comes from the applied electrical signal, the energy given off is due to convection, $\mathrm{q}_{\mathrm{c}}(8)$, and the change in energy of the sample results in a temperature increase (8).

$$
\begin{aligned}
& q_{c}=h A\left(T_{s}-T_{f}\right) \\
& \dot{q_{g}}-\dot{q}_{c}=m C_{p} \frac{d T}{d t}
\end{aligned}
$$

Applying Joules law, and substituting in the expression for convection heat transfer, an expression (9) is obtained for the heat balance of this system [6-8]. 


$$
\frac{V(T)^{2}}{R}-h A_{S} T\left[T(t)-T_{\infty}\right]=m C_{p} \frac{d T}{d t}
$$

Where $\mathrm{V}(\mathrm{t})$ is the voltage potential across the length of the sample, $\mathrm{R}$ is the effective resistance of the sample, $A_{S}$ is the surface area, $T_{\infty}$ is the ambient (or film) temperature of the surrounding air, $m$ is the mass of the sample, $\mathrm{C}_{\mathrm{p}}$ is the materials specific heat, and $\mathrm{T}$ is the temperature of the sample at any point along the length [7]. Re-arranging this expression yields the following first order, linear, ordinary differential equation:

$$
\begin{aligned}
& m C_{p} \frac{d T}{d t}+h A_{S} T=\frac{V(t)^{2}}{R}+h A_{S} T_{\infty} \\
& f(t)=\left[\frac{V(t)^{2}}{R}+h A_{S} T_{\infty}\right]\left[\frac{1}{m C_{p}}\right]
\end{aligned}
$$

Simplying

$$
\begin{aligned}
& m C_{p} \frac{d T}{d t}+p T(t)=f(t) \\
& p=\frac{h A_{S}}{m C_{P}}
\end{aligned}
$$

Verifying homogeneity by undetermined coefficients [7]

$$
\begin{aligned}
& T(t)=A e^{-c t}+B \\
& T(t)=e^{-p t}\left[\frac{c}{p} e^{p t}+\left(T_{\infty}-\frac{c}{p}\right)\right]
\end{aligned}
$$

Time constant

$$
\tau=\frac{1}{p}=\left[\frac{h A_{S}}{m C_{P}}\right]^{-1}
$$

\subsection{MISO System (Multiple Input Simple Output)}

In order to see how closely the current model can control temperature, a model input power is required to cause a desired temperature increase. It is important to note that the applied signal, $\mathrm{V}(\mathrm{t})$, is modelled as a unit step function multiplied by the magnitude of the voltage [9]. The Laplace transform of this term can be written as [7]:

$$
£\left[\frac{\mathrm{V}(\mathrm{t})^{2}}{R}\right]=\frac{\mathrm{V}(\mathrm{t})^{2}}{R} £[\mathrm{u}(\mathrm{t})]=\frac{\mathrm{V}(\mathrm{s})^{2}}{R s}
$$

Where $\mathrm{u}(\mathrm{t})$ is a unit step or pulse generator input. For the entire solution, we start with the original differential equation (17) and apply the Laplace Transformation:

$$
\left(m C_{p}\right)\left[s T(s)-T_{o}(s)\right]+\left(h A_{S}\right) T(s)=\frac{V(s)^{2}}{R} \frac{1}{s}+\left(h A_{S}\right) T_{\infty}(s)
$$

As a function of instantaneous temperature, T(s), initial temperature, To(s), and ambient temperature, $\mathrm{T}_{\infty}(\mathrm{s})$. This expression can then be written in block form and defines the open-loop controller applied to the 
system in Figure 1. Notice that both the ambient temperature, $\mathrm{T}_{\infty}(\mathrm{s})$, and initial temperature, $\mathrm{T}_{\mathrm{o}}(\mathrm{s})$, are factors in the performance of this controller (Figure 1). If these values are the same and the temperature, $\mathrm{T}(\mathrm{s})$, is defined as the increase in temperature from its initial value [9].

$$
T(s)=\Delta\left[T(s)-T_{\infty}(s)\right]
$$

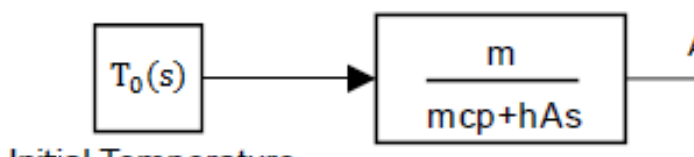

Initial Temperature

A

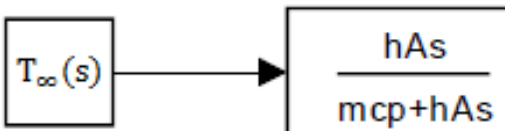

Ambient Temperature
B

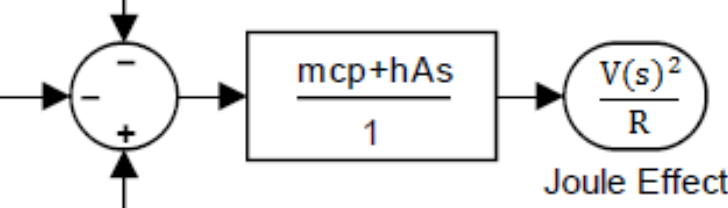

$$
\mathrm{T}(\mathrm{s})
$$

\section{Instantaneous Temperature}

Figure 1: Model System open-loop block diagram.

Open-Loop System

$$
[\mathrm{C}-\mathrm{B}-\mathrm{A}] D=\frac{\mathrm{V}(\mathrm{s})^{2}}{R}
$$




\section{RESULTS AND DISCUSSION}

The block diagram represents the model system, which is shown in Figure 2. In comparison with Figure 1, the zero located at the end is eliminated due to the origin nearness [9].
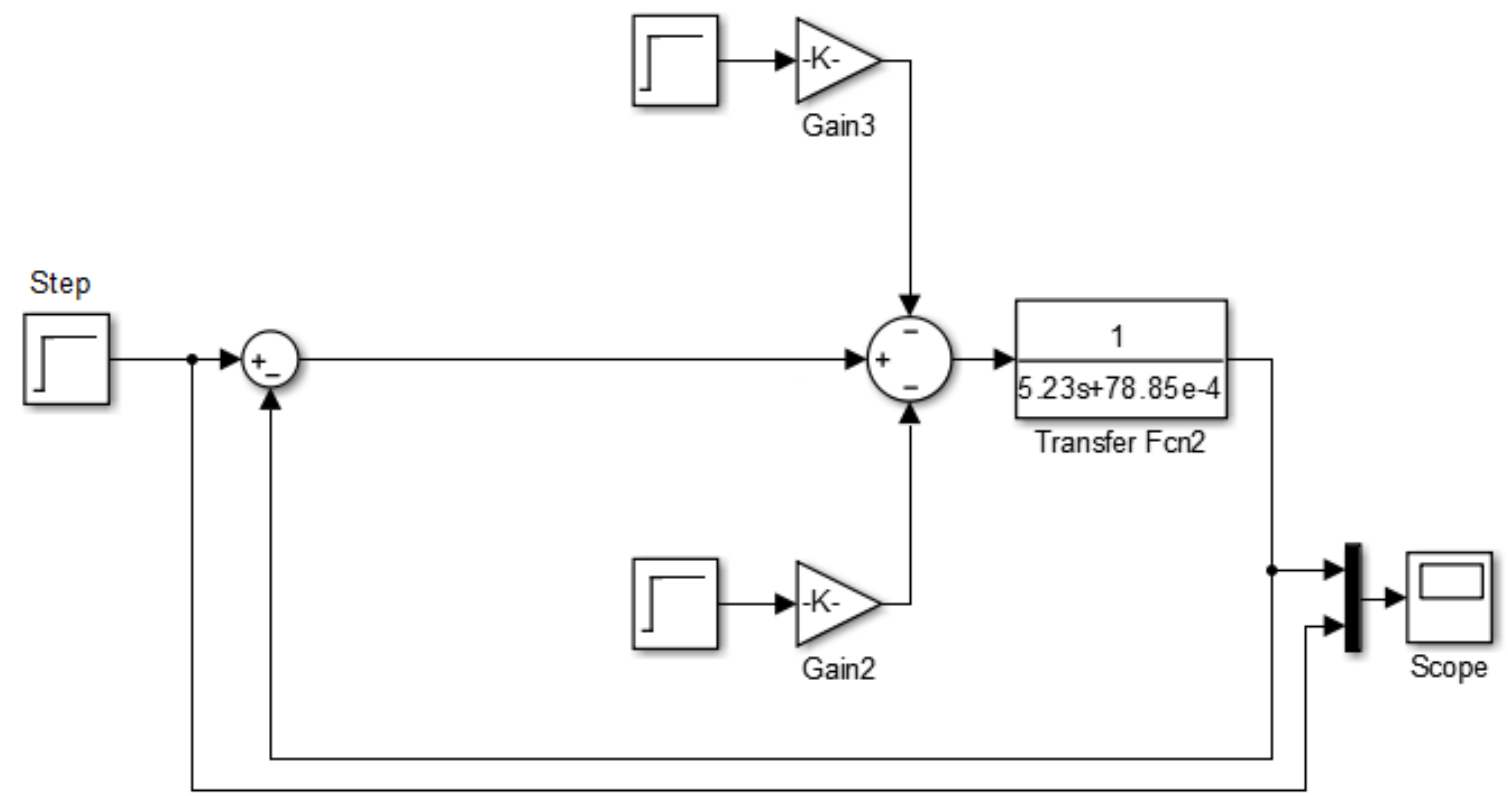

Figure 2: Closed-Loop System.

The model system is written in Simulink, which is a tool from MATLAB, it is also simulated for analysing its stability [10]. The Spark Plasma Sintering Process requires one step current source so that it is placed in each input representing the temperature phenomena. The step limit is at 1 for a practical analysis.

The model constants are from titanium element. The system instability is shown in Figure 3 due to the magnitude decrease crossing the zero reference.

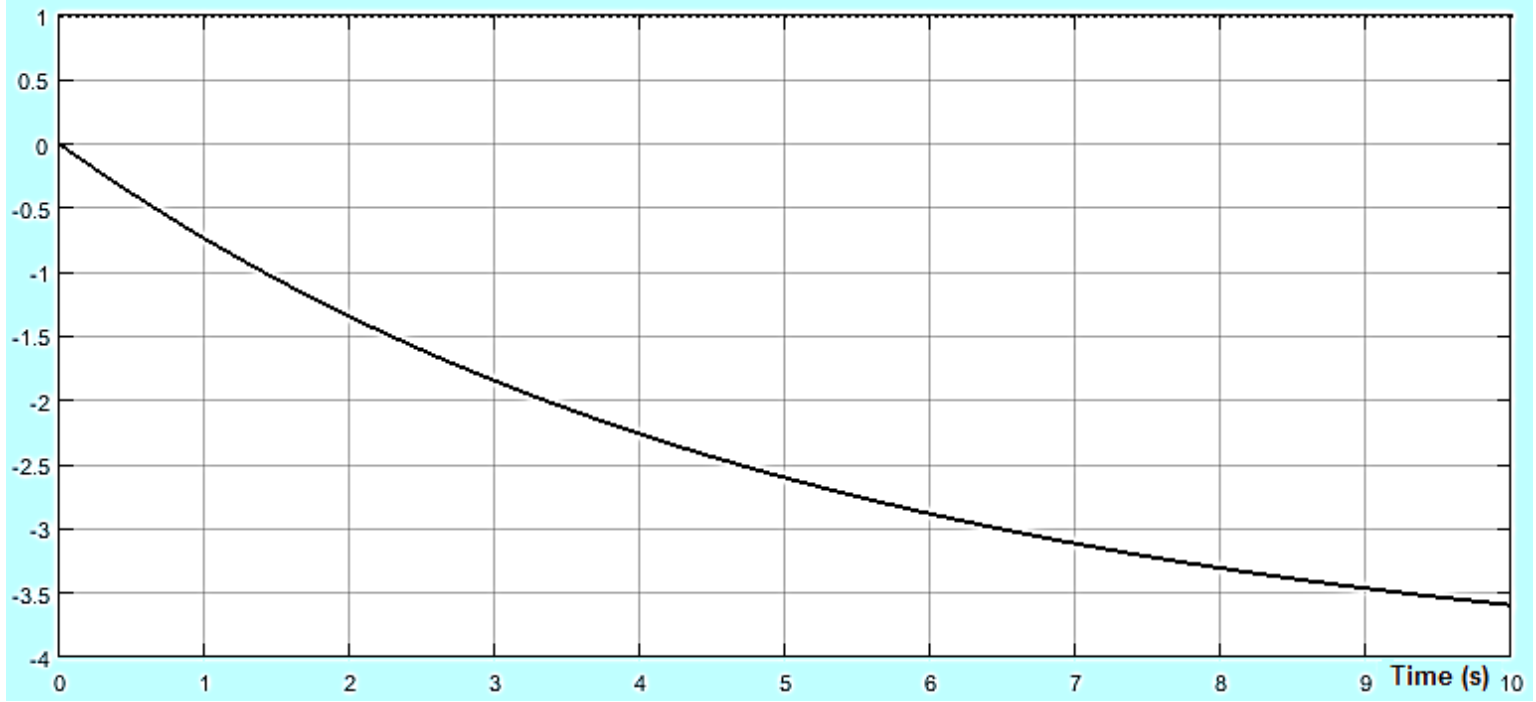

Figure 3: Response System in Closed-Loop.

A PI controller (Proportional-Integral) is proposed [10], the proportional action will get a rapid response time and the Integral action will eliminate the error in steady state. The derivative action is excluded 
due to the oscillations it generates, and the temperature limits do not have to be overtaken in Sintering Process $[11,12]$.

The following math operations are calculated for the controller:

$$
\left[s+15.07 \times 10^{-4}\right] Y(s)=0.1912 K_{p}[r(s)-y(s)]+0.1912 K_{i}\left[r(s)-\frac{y(s)}{s}\right]
$$

It is proposed a $\xi=0.8$ and a $\mathrm{T}_{\mathrm{p}}=0.5 \mathrm{~s}$. These values are equation chacteristics of time response for a second-order control system. They are substituted in Maximum Overshoot and Peak Time formulas in order to get the constants $\mathrm{K}_{\mathrm{p}}$ and $\mathrm{K}_{\mathrm{i}}[12,13]$.

The PI controller is calculated and implemented in a close-loop control, the ambient and initial temperatures are considered as disturbances. The simulation is computed and simulated in Simulink (Figure 4) $[14,15]$.

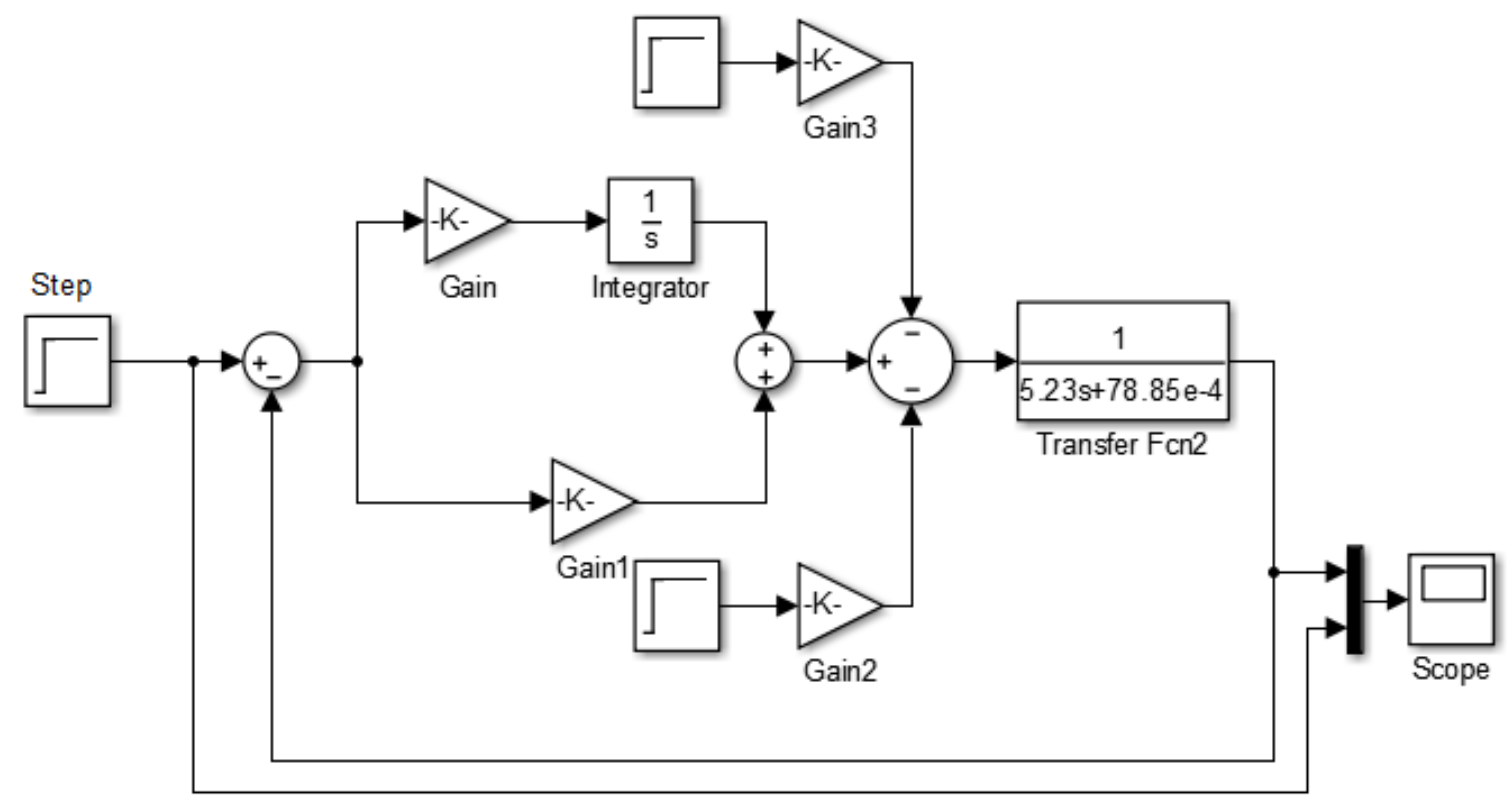

Figure 4: Implemented PI Controller in Closed-Loop System.

The system behavior with the implemented PI controller in close-loop is shown in Figure 5. So this controller proposal improves the dynamic system in 2 seconds [16]. 


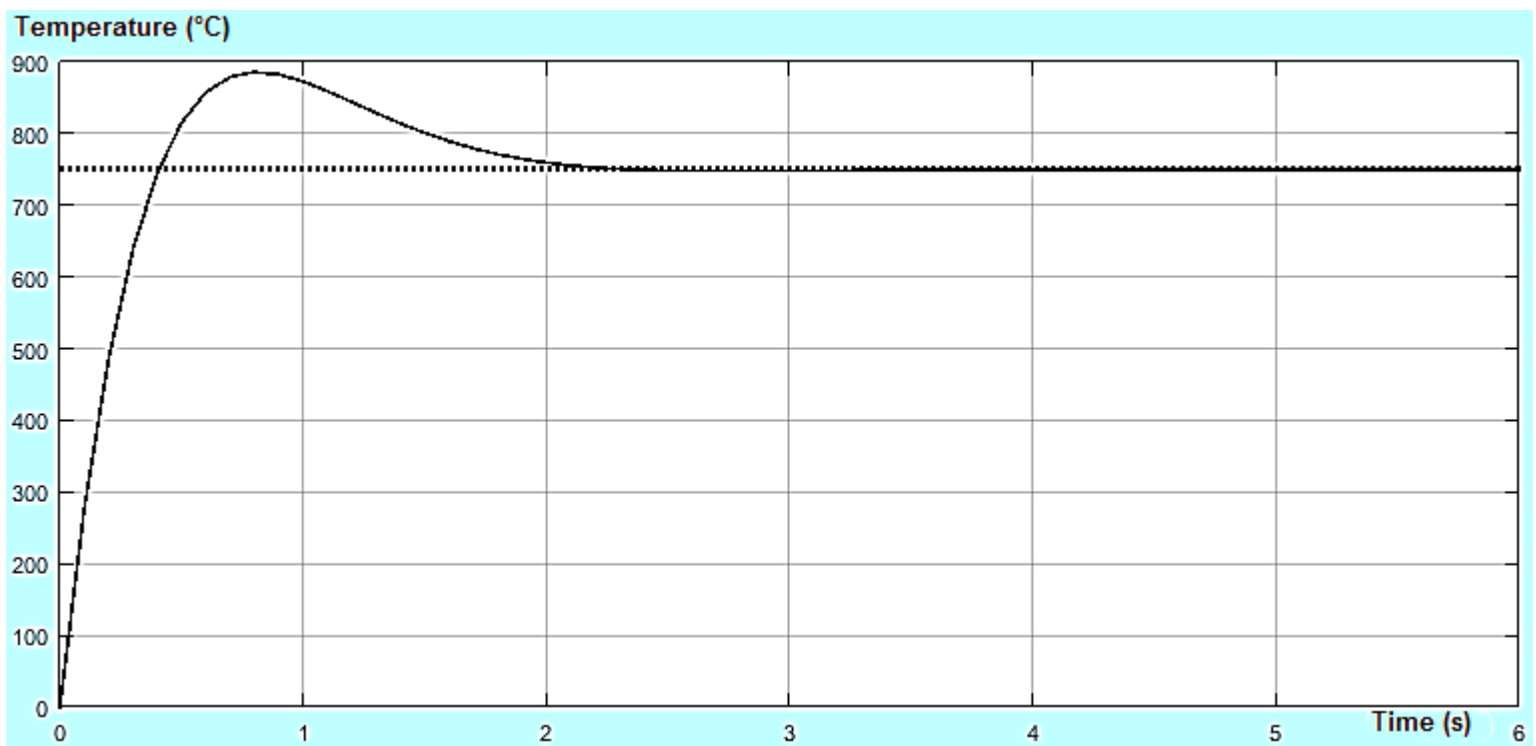

Figure 5: Final Response with the PI Controller.

\section{CONCLUSIONS}

To have obtained the experimental temperature of the sintering machine, it is analysed the lack of precision on operational limits which affect the sintered material. The error existence between the required and experimental temperature induces a crystalline phase in sodium chloride when the 750 Celsius are overtaken due to the melting point. In cases of ceramics and polymers, a different material is obtained. To have proposed a PI controller, the time response is improved and the signal control is stabilized when the error is detected. Besides, the operational limits are not overtaken and the temperature is stable during the process. The conclusions should be concise and represent the most important aspects found during the reported work development. They should seek to point out the scientific and/or technological and/or theoretical progress effectively achieved.

\section{ACKNOWLEDGMENTS}

The authors wish to thank the National Polytechnic Institute (IPN-Mexico) for the financial support granted through SIP20161081 project.

\section{BIBLIOGRAPHY}

[1] GERMAN, R. M. "History of sintering: empirical phase”, Powder Metal, v. 56, n. 2, pp. 117 - 123, 2013.

[2] MUNIR, Z. A., ANSELMI-TAMBURINI, U., OHYANAGI, M. "The effect of electric field and pressure on the synthesis and consolidation of materials: A review of the spark plasma sintering method", Journal Materials Science, v. 41, n. 3, pp. 763 777, 2006.

[3] RAMAKRISHNAN, B., ZHU, L., PITCHUMANI, R. "Curing of composites using internal resistive heating”. ASME Journal of Manufacturing Science and Engineering, v. 131, pp. 122-124, 2000.

[4] SARLES, S. A. "Controlled Resistive Heating of Carbon Fiber Composites", Virgin Tech, pp. 1860, 2006.

[5] INCROPERA, F., DEWITT, D. Fundamentals of Heat and Mass Transfer, John Wiley \& Sons, Inc., 5th Ed., New York, NY, 2002.

[6] TIPLER, P., MOSCA, G. Physics for Scientists and Engineers, $5^{\text {th }}$ Ed. W.H. Freeman and Company, New York, NY, 2004.

[7] ZILL, D., CULLEN, M. Differential Equations with Boundary-Value Problems, Brooks/Cole Publishing Co., 4th Ed., Pacific Grove, CA, 1997.

[8] G. CAO, "Modeling of SPS Apparatus: Temperature, Current and Strain" Distribution with No Powder, v. 53, n. 3, pp. 703-719, 2007.

[9] DORF, R., BISHOP, R. "Modern Control Systems", In: Prentice-Hall, 9th Ed. Inc., Upper Saddle River, NJ, 2001. 
[10] FERREYRA, R. F. A. "Estudio comparativo entre control PID y difuso", Control Des. SOMI XV, v. 8, n. pp. 52-57, 2015.

[11] ANDERSON, D. R., CONNOLLY, F. X., MUNKHOLM, H. J. "A comparison of continuously controlled and controlled limite", v. 8641, n. 1, 1996.

[12] DAVENDRA, D., ZELINKA, I., SENKERIK, R. "Chaos driven evolutionary algorithms for the task of PID control”, Comput. Math. With Appl., v. 60, n. 4, pp. 10881104, 2010.

[13] HENRIQUES, J. "Supervision and c-Means clustering of PID controllers for a solar power plant", International Journal of Approximate Reasoning, v. 22, pp. 73-91, 1999.

[14] LAN, L. H. "Stability analysis for a class of Takagi Sugeno fuzzy control systems with PID controllers", v. 46, pp. 109119, 2007.

[15] TORNAMB, A. "A PID controller for the robust stabilization linear systems", Applied Mathematics Letters, v. 5, n. 4, pp. 1518, 1992.

[16] GARCA-SANZ, M. "A reduced model of central heating systems as a realistic scenario for analyzing control strategies”, n. 97, pp. 535-545, 1997. 